\title{
Hyperbilirubinemia in Neonatal Intensive Care Unit: Incidence And Etiology at Fayoum University Hospital.
}

\author{
Ahmed M. Abd El Moktader ${ }^{(1)}$, Sherin K. Hussein ${ }^{(2)}$, Mohamed G. M. Boraik $^{(3)}$ \\ (1) MD Professor of Pediatrics ,Faculty of Medicine,Fayoum University. \\ (2) MD Lecturer of Pediatrics,Faculty of Medicine,Fayoum University. \\ (3) M.B.B.CH, Pediatrics department,Faculty of Medicine,Fayoum University.
}

Corresponding author: Dr. Ahmed Mahmoud Abd Elmoktader,

E-mail: ama13@fayoum.edu.eg

Fax: 0846302350

Tel: 0846300587

\begin{abstract}
Although most of newborns develop some degree of jaundice, bilirubin levels high enough to put a newborn at risk of bilirubin encephalopathy and kernicterus are rare but still occur in Egypt.

The aim of current study was to assess the magnitude of neonatal jaundice and detect possible etiologies. This study included prospective analysis of the data of all jaundiced cases admitted to NICU of Fayoum University Hospital during the period from the first of july 2017 to the end of June 2018 (one year) .

In the study period, among 366 patients admitted to the NICU, there were 167 patients having neonatal jaundice who were admitted to neonatal intensive care unit with a mean age of $5.96 \pm 3.88$ days and a mean weight of $2940 \pm 390$ grams. They represented $45.6 \%$ of all cases admitted in the period of study.
\end{abstract}

The mean total bilirubin level at day of presentation was $19.89 \pm 4.85 \mathrm{mg} / \mathrm{dl}$. It was found that ABO incompatibility, $\mathrm{Rh}$ incompatibility and G6PD deficiency $(29.9 \%, 8.4 \%$ and $1.8 \%$ respectively) are the main causes of indirect hyperbilirubinaemia. In $56.3 \%$ of cases the cause was exaggerated physiological.

Phototherapy was the only therapy in $56.3 \%$ of cases while $32.9 \%$ required Intensive photo (Bilisphere) and $10.8 \%$ required exchange transfusion.

\section{KEY WORDS: Neonatal jaundice, hyperbilirubinemia, kernicterus, neonates. INTRODUCTION}

One of the most prevalent clinical conditions in neonates is hyperbilirubinemia (Olusanya et al., 2015 ). Neonatal hyperbilirubinemia is a common clinical problem encountered during the neonatal period, especially in the first week of life (Bhutani et al., 2013).

Nearly $8 \%$ to $11 \%$ of neonates develop hyperbilirubinemia. When the total serum bilirubin (TSB) rises above the $95^{\text {th }}$ percentile for age (high-risk zone) during the first week of life, it will be considered as hyperbilirubinemia (Burke et al., 2009).

Between $60 \%-80 \%$ of healthy infants are expected to present with idiopathic neonatal jaundice. Neonatal jaundice is the discoloration of skin and sclera color to yellowish in a newborn (Ogunfowora et al., 2006 ).

Several types of hyperbilirubinemia have been reported in neonates including physiological jaundice, pathological jaundice, 
jaundice due to breastfeeding or breast milk and hemolytic jaundice including three subtypes due to Rh factor incompatibility, ABO blood group incompatibility and Jaundice associated with Glucose-6-phosphate dehydrogenase (G6PD) deficiency (Mishra et al., 2008).

The most common causes of early neonatal jaundice (Onset less than $24 \mathrm{~h}$ ) are

\section{SUBJECTS AND METHODS}

\section{Subjects:}

One hundred sixty seven (167) was the total number of neonatal jaundice cases who were included in the study. All of them had total serum bilirubin level above $6 \mathrm{mg} / \mathrm{dl}$ and were admitted in the Neonatal Intensive Care Unit (NICU) of Fayoum University Hospital during the period from the first of july 2017 to the end of June 2018 (one year). Their mean age of $5.96 \pm 3.88$ days and a mean weight of $2940 \pm 390$ grams. They represented $45.6 \%$ of all cases admitted in the period of study. The mean total bilirubin level at day of presentation was $19.89 \pm 4.85 \mathrm{mg} / \mathrm{dl}$.

\section{Methods:}

Prospective data of all neonatal jaundice cases admitted in NICU of Fayoum University Hospital was collected and descriptive analysis of these data was done.

1-Full history with focusing on : date of birth, gender, onset of jaundice and if there are any problems associated with jaundice as respiratory distress or sepsis, gestational age with perinatal and past history for maternal

\section{RESULTS}

Incidence of jaundice among neonates attending NICU at Fayoum University
Haemolytic disease: eg, haemolytic disease of the newborn (rhesus), ABO incompatibility, glucose-6-phosphate dehydrogenase deficiency, spherocytosis. Infection: congenital (eg, toxoplasmosis, rubella, cytomegalovirus (CMV), herpes simplex, syphilis) or postnatal infection (Stevenson et al., 2011).

illness, history of drug intake, birth trauma or previous sibling with neonatal jaundice.

2- Examination of the newborn: including weight, temperature and overall inspection for general appearance, alertness and skin to assess extent of jaundice and detect pallor. Neurological examination including muscle tone and reflexes and also signs suggestive of kernicterus.

\section{3- Laboratory investigations:}

- Total and direct bilirubin level.

- Complete blood count and reticulocytic count.

- C-reactive protein.

- Maternal, infant blood groups ABO and Rh and Coombs' test to suspected cases with hemolytic jaundice.

- G6PD activity assay in suspected cases.

\section{4- Therapy :}

Most of cases received phototherapy and some cases received intensive phototherapy (Bilisphere) while exchange transfusion was done to indicated cases only.

Hospital in the period between July 2017 to June 2018: $($ No $=366)$

Table (1): Incidence of Neonatal Jaundice:

\begin{tabular}{|l|c|c|}
\hline \hline & No & $\%$ (95 \% confidence interval CI) \\
\hline Having jaundice & 167 & $45.6(40.5-50.7)$ \\
\hline Having other conditions & 199 & 54.4 \\
\hline Total & 366 & 100.0 \\
\hline
\end{tabular}


Regarding gender, 90 (53.9\%) of neonates with jaundice in our study were males and $77(46.1 \%)$ were females as shown in figure (1) .

\section{Figure (1): Prevalence of Neonatal Jaundice According to Gender}

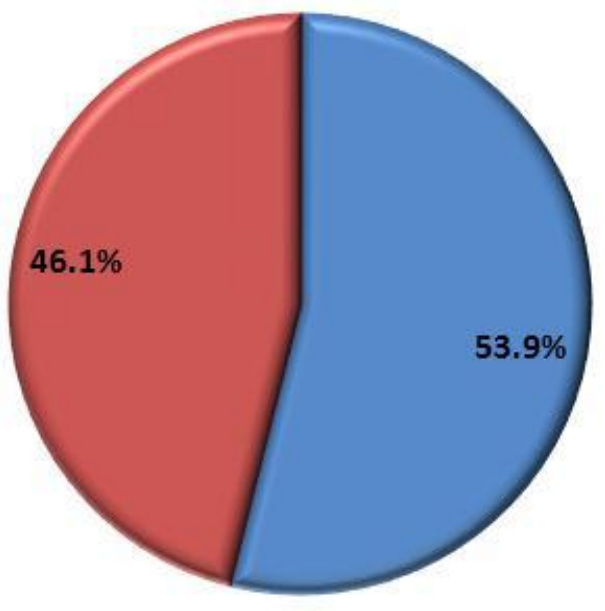

Sex:

回Male

回Female

Figure (2) showed the relationship between jaundice prevalence and mode of delivery. The prevalence of jaundice in neonates delivered by NVD was $28.1 \%$ and $71.9 \%$ in neonates delivered by CS.

Figure (2): Relation of Jaundice Prevalence to Mode of delivery

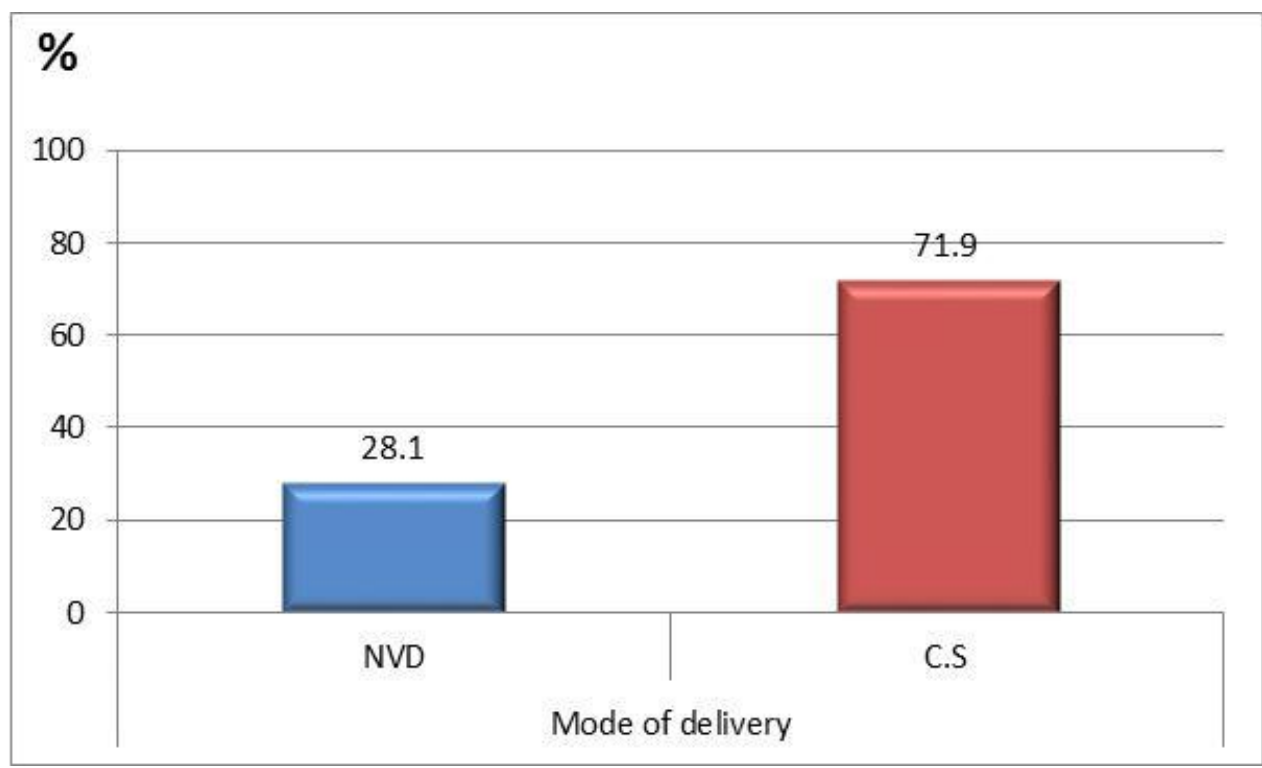

Table (2): Most of neonates with jaundice $94 / 167(56.3 \%)$ were diagnosed as exaggerated physiological jaundice, then $50 / 167(29.2 \%)$ as $\mathrm{ABO}$ incompatibility,
14/167 (8.4\%) as RH incompatibility, 3/167 (1.8\%) ABO \& RH incompatibility, 3/167 $(1.8 \%)$ as G6PD deficiency and 3/167 (1.8\%) as sepsis. 


\begin{tabular}{|l|c|c|}
\hline \multicolumn{1}{|c|}{ Variable } & No & \% \\
\hline \hline \multicolumn{2}{|c|}{ Etiology: } \\
\hline Exaggerated physiological & 94 & 56.3 \\
\hline ABO incompatibility & 50 & 29.9 \\
\hline RH incompatibility & 14 & 8.4 \\
\hline ABO \& RH incompatibility & 3 & 1.8 \\
\hline G6PD deficiency & 3 & 1.8 \\
\hline Sepsis & 3 & 1.8 \\
\hline
\end{tabular}

Table (2): Etiology of Neonatal Jaundice

Figure (3) : Most of neonates with jaundice 94/167 (56.3\%) were diagnosed as exaggerated physiological jaundice, then $50 / 167(29.2 \%)$ as ABO incompatibility,

Figure (3): Etiology of Neonatal Jaundice
14/167 (8.4\%) as RH incompatibility, 3/167 (1.8\%) ABO \& RH incompatibility, 3/167 $(1.8 \%)$ as G6PD deficiency and 3/167 (1.8\%) as sepsis.

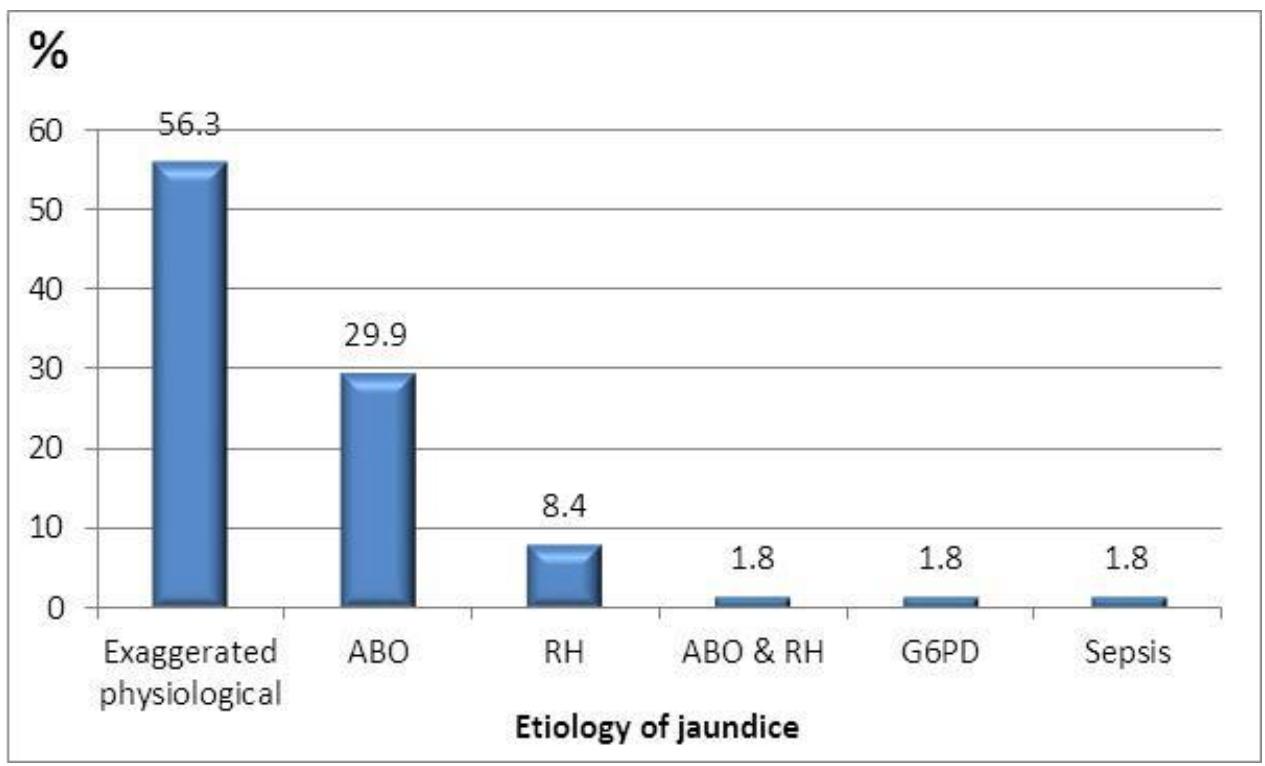

Regarding mode of treatment in our study, we found that the incidence of hyperbilirubinemic neonates received phototherapy was $56.3 \%$ $(94 / 167)$, and the incidence of neonates who received intensive photo (Bilisphere) was 32.9
$\%(55 / 167)$, and the incidence of neonates who received exchange transfusion and photo was $10.8 \%(18 / 167)$ as shown in table (3) . Table (3): Types of Treatment of Neonatal Jaundice Cases 
By comparing total bilirubin level between admission and discharge, there was a reduction in serum total bilirubin from at-admission compared to at-discharge (19.89 \pm 4.85 vs. $9.99 \pm 1.25)$, which was statistically significant $(\mathrm{p}<0.0001)$ figure $(4)$.

\section{Figure (4): Total Bilirubin in Neonates at Admission and at Discharge}

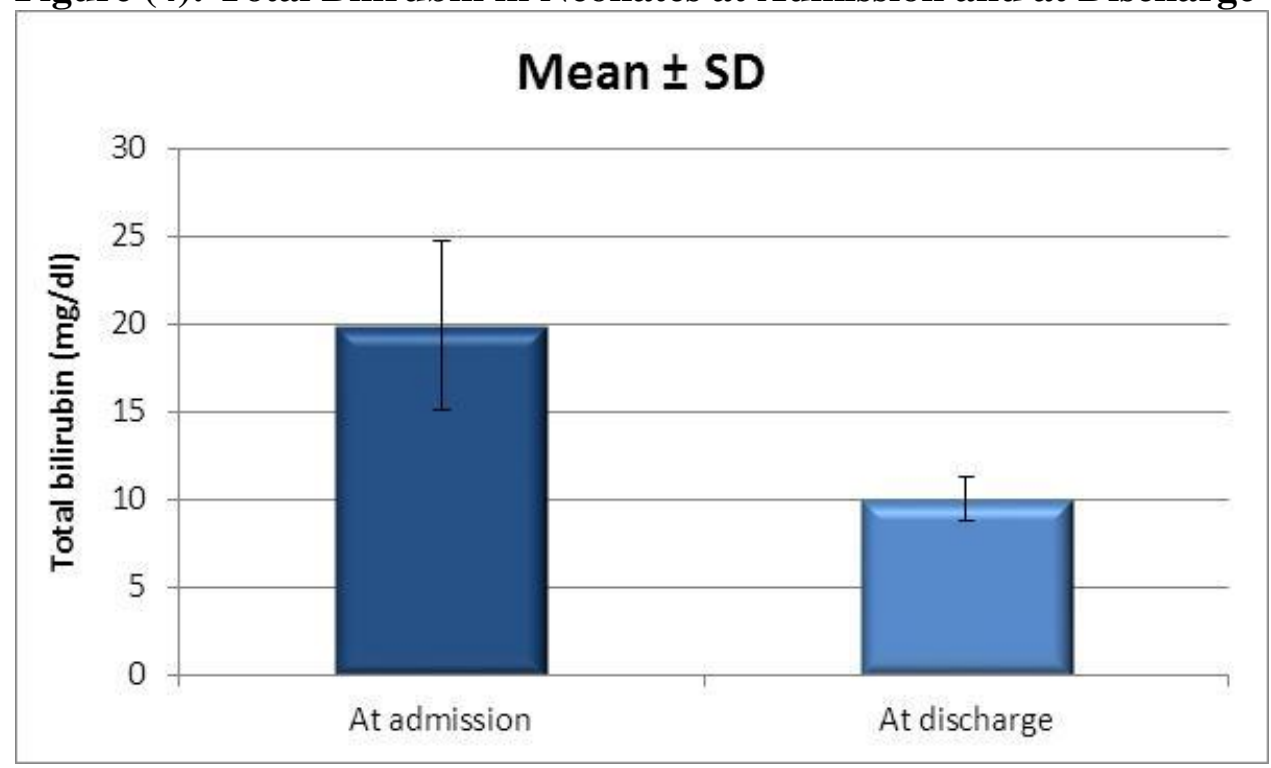

\section{DISCUSSION}

Among 366 patients admitted to the NICU during the period from the first of july 2017 to the end of June 2018, the incidence of neonatal jaundice in our study was $45.6 \%$. The study included 167 neonates with clinical jaundice who had serum bilirubin level above $6 \mathrm{mg} / \mathrm{dl}$.

In a study in Jawahar Lal Nehru Medical College and Hospital, Bhagalpur, Bihar, India during the period from June 2016 to July 2017, out of 280 newborns, 136 (48.57\%) newborns developed clinical jaundice (Pawan et al., 2018).

In another study that was conducted in neonatal unit, Department of Pediatrics, Saidu group of Teaching Hospital, Swat, Pakistan, from 1 July 2016 to 31 December 2016, Out of 550 newborns admitted to neonatal unit, 201(36.54\%) patients had jaundice

\section{(IhsanulHaq et al., 2017).}

In Iran, Neonatal hyperbilirubinaemia, defined as a total serum bilirubin level above 5 $\mathrm{mg} / \mathrm{dl}$, accounts for up to $75 \%$ of hospital readmissions in the first week of life (Koosha and Rafizadeh, 2007).
In our study the age of patients on admission ranged between 1 and 20 days with mean age of $5.96 \pm 3.88$ days compared to study by Seoud et al in 2007 which showed that admission ranged from 6-24 days with a mean of $10.8 \pm 3.69$ days.

There was a higher incidence of males $(58.7 \%)$ compared to females $(41.3 \%)$ in our study. The same male predominance was reported by Tiker et al in 2006 in a study in Baskent University, Turkey and Hassan et al in 2000 in a study in Children's Hospital - Cairo University.

A study was conducted in Neonatal Intensive Care Unit, Gauhati Medical College and Hospital, India, over a period of one year (February 2015 to January 2016), out of 520 jaundiced neonates 302 (58.08\%) were males and 218 (41.92\%) females (Dulal et al., 2016).

Regarding the cause of jaundice in our study, we found that $56.3 \%$ of cases had exaggerated physiological jaundice and $43.7 \%$ had pathological jaundice. 
ABO incompatibility and $\mathrm{Rh}$ incompatibility accounts for $29.9 \%$ and $8.4 \%$ of jaundiced cases respectively.

Close results were reported by Seoud et al in 2007, 23\% and 10.9\% had ABO and Rh incompatibility respectively.

In our study, phototherapy was used for $56.3 \%$ (94/167), and intensive photo (Bilisphere) was used for $32.9 \%(55 / 167)$. Cases that didn't respond to phototherapy or had markedly elevated TSB at presentation were managed by exchange transfusion and were placed on phototherapy while exchange transfusion was prepared and $10.8 \%(18 / 167)$ of our cases required exchange transfusion.

In a study in Pakistan, all jaundiced patient received phototherapy, exchange blood transfusion was done in 37patients (18.40\%), double exchange transfusion was done in 3 patients (1.49\%) (IhsanulHaq et al., 2017).

\section{Conclusions and Recommendations}

- Neonatal Jaundice is a major problem in the NICU of Fayoum University Hospital and the incidence seems to be increasing.
- The frequent causes of unconjugated hyperbilirubinemia in our population are ABO incompatibility, Rh incompatibility and sepsis. Exaggerated physiological jaundice is present in a big number of cases.

- Early management with phototherapy alone or with exchange transfusion in indicated cases significantly decline the total serum bilirubin levels on follow up of cases and improve the outcome.

- Improving the antenatal care services and obstetric practices for the prevention and early control of neonatal hyperbilirubinemia.

- Screening all newborns before discharge from maternity hospital and check level on hour specific normogram to detect risk of severe hyperbilirubinemia and give them appointment to follow up.

- Encouragement of early breast feeding and lactation support.

- Parental education about jaundice and proper timely follow up is essential.

\section{REFERENCES}

[1] Bhutani VK, Zipursky A, Blencowe H, Khanna R, Sgro M,EbbesenF. (2013). Neonatal hyperbilirubinemia and Rhesus disease of the newborn: incidence and impairment estimates at regional and globallevels. Pediatr Res, 1 : 86-100.

[2] Burke BL, Robbins JM, Bird TM, Hobbs CA, Nesmith C, TilfordJM. (2009). Trends in hospitalizations for neonatal jaundice and kernicterus in the United States, 1988-2005. Pediatrics, 123: 524-32.

[3] Dulal K, Gyanam M, Vivekananda M S (2016): aetiological profile of neonatal hyper bilirubinemia in neonatal intensive care unit of guahati medical college and hospital, J. Evolution Med. Dent. Sci;5(34): 2278-4748.

[4] Hassan Z, Seoud IA, Ghobasi $M$ and El Miniawi N (2000): Outcome of neonatal admissions to the intensive care unit in New Children Hospital Cairo Universty (thesis Msc) Faculty of medicine.

[5] IhsanulHaq, IsrarulHaq, Sardar K, Zahir S (2017): common aetiological spectrum of indirect hyperbilirubinemia in neonates,JSMC,7(2):112116. 
[6] Koosha A and Rafizadeh B (2007): Evaluation of neonatal indirecthyperbilirubinaemia at Zanjan Province of Iran in 2001-2003: prevalence ofglucose-6-phosphate dehydrogenase defi ciency. Singapore Med J ; 48 (5):424-428.

[7] Mishra S, Agarwal R, Deorari AK, Paul VK. (2008). Jaundice in the newborns. Indian $\mathbf{J}$ Pediatr, 75(2): 157-163.

[8] Ogunfowora OB, Daniel OJ. (2006): Neonatal jaundice and its management: Knowledge, attitude and practice of community health workers in Nigeria. BMC Public Health, 6: 19.

[9] Olusanya BO, Osibanjo FB, Slusher TM. (2015): Risk factors forsevere neonatal hyperbilirubinemia in low and middle-income countries:a systematic review and metaanalysis. PLoS One, 10.
[10] Pawan K Y,Anil K, Brajesh K (2018): A study of neonatal jaundice in a tertiary care centre in Eastern Bihar, Indian journal of applied;8(8).research.

[11] Seoud IA, Iskander IF, Gamal El-Din RM and Salam MM (2007): Neonatal jaundice in the NICU: An old topic revisited. Journal of Arab Child;18(2): 99-108.

[12] Stevenson D.K., Vreman H.J., Wong R.J. (2011). Bilirubin production and the risk of bilirubin neurotoxicity. Semin. Perinatol ;35(3):121126.

[13] Tiker F, Gulcan H, Kilicdag $H$, Tarcan $A$ and Gurakan B(2006): Extreme hyperbilirubinemia in newborn infants. Clin Pediatr ;45:257261(a). 